\section{Relation of urinary total hydroxyproline: creatinine ratio to height velocity in children with retarded growth}

The excretion of hydroxyproline-containing peptides in urine is related to collagen turnover and thus should reflect growth rate in children (Jasin et al., 1962; Smiley and Ziff, 1964; Younoszai et al., 1967; Zorab et al., 1970). Allison, Walker, and Smith (1966) showed that the ratio of total hydroxyproline to creatinine in a 24-hour collection of urine gives more consistent results than measurement of hydroxyproline alone, an observation which has been extended to random samples of urine collected during waking hours (Howells, Wharton, and McCance, 1967; Younoszai et al., 1969).

Wharton et al. (1972) have defined the normal range for total hydroxyproline : creatinine ratios in random urine samples collected from British children, and they also showed a similarity between the excretion pattern according to age, and the pattern of growth velocity defined by Tanner, Whitehouse, and Takaishi (1966). They suggested a number of possible clinical uses for the hydroxyproline: creatinine estimation, and in particular that it might be a useful adjunct to anthropometry and radiology in assessment of growth. The estimation of the total hydroxyproline:creatinine ratio has been found to be valuable in the management of children with growth hormone deficiency (Wharton et al., 1974). In particular, Wharton and his coauthors showed that the increase of total hydroxyproline in response to growth hormone correlated well with increase in height. Thus it appeared to be a useful index of therapeutic response. However, the large majority of children whose growth is retarded do not have an absolute deficiency of growth hormone.

At the present time the only method for assessing the rate at which such children are growing is by regular measurements over at least 6 months or preferably one year. As it seemed possible that the total hydroxyproline:creatinine ratio would be a useful index of growth rate in children who are small for their chronological age, but in whom absolute growth hormone deficiency has been excluded, this study was undertaken.

\section{Methods}

Eighteen boys and 11 girls referred to a children's hospital because of small stature were included in the study. Any serious degree of growth hormone deficiency was excluded by finding one or more serum growth hormone levels of at least $10 \mu \mathrm{U} / \mathrm{ml}$ either after exercise or during an insulin tolerance test. When first examined, the patients' heights and weights were recorded and at least two midmorning specimens of urine were collected for estimation of total hydroxyproline (Pennock et al., 1970). Height and weight were compared with age using growth and development charts prepared by Tanner et al. (1966) and the average total hydroxyproline : creatinine ratio compared with age using the data given by Wharton et al. (1972). The children were all seen at intervals as outpatients for at least one year, and the height and weight were recorded at each visit. The mean height velocity per year was calculated and compared with chronological age using the height velocity charts of Tanner et al. (1966).

\section{Results}

The age of the children when first examined and their height centile, hydroxyproline centile, and height velocity centile for growth in the following year are shown in the Table. The relation of the hydroxyproline excretion centile to the height velocity centile for each child is shown in an alternative form in the Fig., which illustrates the fact that some children with a hydroxyproline:creatinine ratio below the 10th centile were growing normally while others with a normal ratio, were not growing normally as reflected by their height velocity. The hydroxyproline :creatinine ratio is an average of up to six and not less than two urine samples. Individual values were similar and on no occasion would an individual result have changed the category in which the child was placed on the basis of the average result for that child.

\section{Discussion}

Teller et al. (1973) have shown that children with dwarfism due to hormone deficiency have lower hydroxyproline excretion than primordial dwarfs. Our data lend some support to this 
TABLE

Height, height velocity, and hydroxyproline excretion centiles

\begin{tabular}{|c|c|c|c|c|}
\hline Case no. & Age (yr) & Height centile & $\begin{array}{l}\text { Hydroxyproline } \\
\text { centile }\end{array}$ & $\begin{array}{l}\text { Height velocity } \\
\text { centile }\end{array}$ \\
\hline $\begin{array}{c}\text { Boys } \\
1 \\
2 \\
3 \\
4 \\
5 \\
6 \\
7 \\
8 \\
9 \\
10 \\
11 \\
12 \\
13 \\
14 \\
15 \\
16 \\
17 \\
18\end{array}$ & $\begin{array}{r}3 \cdot 10 \\
3 \cdot 18 \\
9 \cdot 38 \\
7 \cdot 17 \\
4 \cdot 13 \\
4 \cdot 09 \\
7 \cdot 06 \\
4 \cdot 03 \\
6 \cdot 09 \\
9 \cdot 80 \\
9 \cdot 59 \\
3 \cdot 78 \\
8 \cdot 90 \\
16 \cdot 86 \\
12 \cdot 03 \\
13 \cdot 85 \\
12 \cdot 18 \\
11 \cdot 12\end{array}$ & $\begin{array}{r}<3 \\
=3 \\
<3 \\
<3 \\
<3 \\
=3 \\
=3 \\
<3 \\
<3 \\
<3 \\
3-10 \\
=3 \\
<3 \\
<3 \\
25-50 \\
3-10 \\
<3 \\
<3\end{array}$ & $\begin{array}{r}<10 \\
>90 \\
<10 \\
50-90 \\
10-50 \\
>90 \\
50-90 \\
50-90 \\
10-50 \\
<10 \\
10-50 \\
50-90 \\
50-90 \\
>90 \\
50-90 \\
50-90 \\
50-90 \\
10-50\end{array}$ & $\begin{array}{r}10-25 \\
50-75 \\
75-90 \\
=25 \\
<3 \\
50-75 \\
90-97 \\
=90 \\
=50 \\
=25 \\
25-50 \\
<3 \\
=50 \\
>97 \\
3-10 \\
50-75 \\
=10 \\
=25\end{array}$ \\
\hline $\begin{array}{l}\text { Girls } \\
19 \\
20 \\
21 \\
22 \\
23 \\
24 \\
25 \\
26 \\
27 \\
28 \star \\
29\end{array}$ & $\begin{array}{r}3 \cdot 08 \\
5-84 \\
4 \cdot 09 \\
5 \cdot 94 \\
7 \cdot 75 \\
11 \cdot 25 \\
12 \cdot 34 \\
15 \cdot 12 \\
13 \cdot 84 \\
11 \cdot 60 \\
11 \cdot 69\end{array}$ & $\begin{array}{r}3-10 \\
=10 \\
<3 \\
<3 \\
<3 \\
=3 \\
<3 \\
<3 \\
<3 \\
<3 \\
<3\end{array}$ & $\begin{array}{r}50-90 \\
<10 \\
10-50 \\
<10 \\
50-90 \\
<10 \\
50-90 \\
50-90 \\
50-90 \\
>90 \\
10-50\end{array}$ & $\begin{array}{r}75-90 \\
=25 \\
<3 \\
10-25 \\
=3 \\
3-10 \\
90-97 \\
>97 \\
=75 \\
=75 \\
=3\end{array}$ \\
\hline
\end{tabular}

* Post craniopharyngiomectomy.

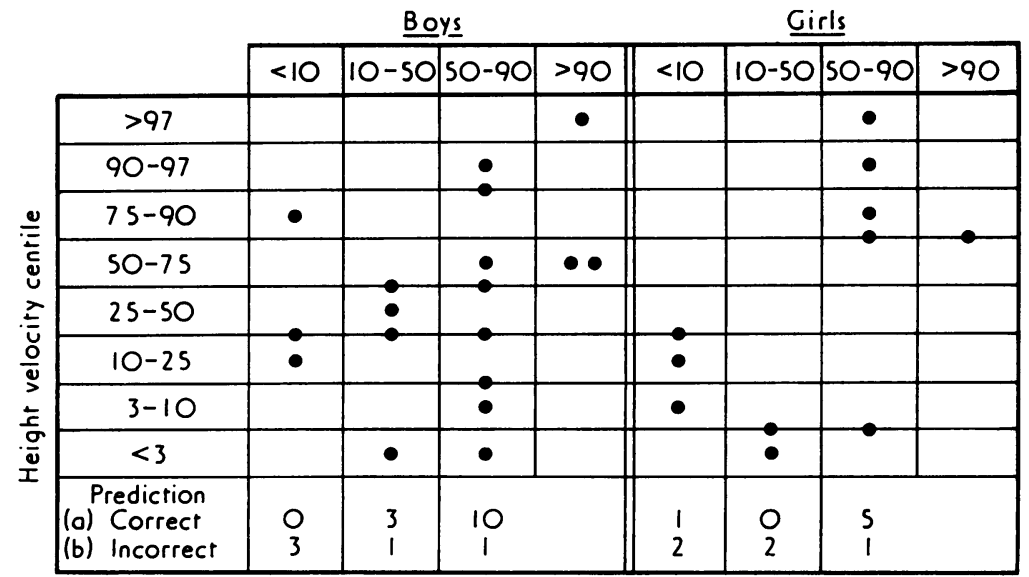

Fig.-The urinary hydroxproline:creatinine ratio centile at the beginning of one year's observation is shown against the height velocity centile subsequently observed during that year. The figures in the bottom portion indicate the number of times a prediction of height velocity would have been correct or incorrect assuming that the hydroxyproline:creatinine ratio may be used as a means of predicting height velocity (see text). 
statement in that only 6 of the 29 children studied gave a hydroxyproline: creatinine ratio below the 10th centile in spite of the fact that their height was below the 3rd centile.

Zorab et al. (1970) have shown that hydroxyproline excretion during adolescence could be used to predict whether or not the child was entering a growth spurt. Our initial hypothesis was that the total hydroxyproline:creatinine ratio (HP index) on midmorning urine samples might be used to predict the height velocity of each patient. If this hypothesis were true, it would be expected that (1) all HP indices below the 10th centile for age would be found in patients whose height velocity was below the 10th centile; (2) all $\mathrm{HP}$ indices above the 10th centile but below the 50th centile for age would be associated with height velocities between these same centiles; (3) all HP indices above the 50th centile for age would be associated with height velocity above this centile.

The Table and Fig. show that the first statement was correct in one girl, but was incorrect in 3 boys and 2 girls inasmuch as the HP index was below the 10th centile though height velocity was normal. Had the HP index been used to predict height velocity it would have been wrong on five out of six $(84 \%)$ occasions. In children with an HP index between the 10th and 50th centiles growth velocity would have been correctly predicted in 3 boys, but incorrectly predicted in 1 boy and 2 girls whose height velocity was at or below the 3 rd centile for their age. Had the HP index been used to predict height velocity it would have been wrong on three out of six (50\%) occasions. The final statement was correct in 10 boys and 5 girls and incorrect in 1 boy and 1 girl whose height velocities were on or below the 3rd centile. Thus, when the HP index was high, good height velocity was predicted on 15 out of 17 occasions ( $80 \%$ ), but the prediction was incorrect on 2 out of 17 occasions (12\%). Our results on children who might reasonably be considered as adolescent partially agree with the findings of Zorab et al. (1970), in that high hydroxproline excretion tends to indicate a growth spurt. However, the prediction would have been little more accurate in adolescents than in younger children.

The overall prediction of height velocity over a year based on measurement of total hydroxyproline:creatine ratio would have been in error on 10 out of 29 occasions $(35 \%)$. The practical importance of this statement is in the fact that if we had made such a prediction in our 6 children with an HP index below the 10th centile we would have assumed that height velocity would be poor in the next year and might have started therapy. We would then incorrectly have ascribed the height velocity above the 10th centile as being due to that therapy. Conversely, in children with an HP index in the normal range or above we might have predicted good growth and not started potentially useful therapy and would have been wrong to do so on $22 \%$ of occasions.

It must be concluded that the estimation of total hydroxyproline:creatinine ratio is not sufficiently reliable to predict height velocity in a growthretarded child, though changes in this ratio may still be useful for monitoring therapy (as shown in growth hormone-deficient children by Wharton et al., 1974). Other factors, including seasonal variation, will affect the ratio, as shown by Wharton, Gough, and Pennock (1973), and the investigation is probably useful only with sequential studies of an individual child over a short period.

\section{Summary}

The urinary total hydroxyproline:creatinine raito was measured on samples collected from 18 boys and 11 girls referred to a children's hospital because of small stature. Any serious degree of growth hormone deficiency was excluded and each child's growth and development was recorded over the following year. The hypothesis that the average hydroxyproline:creatinine ratio on random urine samples may be used to predict height velocity was examined. Such a prediction would have been incorrect on $35 \%$ of occasions, and it is concluded that this investigation cannot be used reliably to predict growth in height; it is probably only useful with sequential studies of an individual child over short periods while monitoring therapy.

\section{REFERENCES}

Allison, D. J., Walker, A., and Smith, Q. T. (1966). Urinary hydroxyproline:creatinine ratio of normal humans at various ages. Clinica Chimica Acta, 14, 729.

Howells, G. R., Wharton, B. A., and McCance, R. A. (1967). Value of hydroxyproline indices in malnutrition. Lancet, 1, 1082.

Jasin, H. E., Fink, C. W., Wise, W., and Ziff, M. (1962). Relationship between urinary hydroxyproline and growth. Fournal of Clinical Investigation, 41, 1928.

Pennock, C. A., Moore, G. R., and Hoyle, M. D. (1970). Estimation of hydroxproline in urine. Fournal of Medical Laboratory Technology, 27, 302.

Smiley, J. D., and Ziff, M. (1964). Urinary hydroxyproline excretion and growth. Physiological Reviews, 44, 30.

Tanner, J. M., Whitehouse, R. H., and Takaishi, M. (1966). Standards from birth to maturity for height, weight, height velocity and weight velocity: British children, 1965, Part II. Archives of Disease in Childhood, 41, 613.

Teller, W. M., Genscher, U., Burkhardt, H., and Rommel, K. (1973). Hydroxyproline excretion in various forms of growth failure. Archives of Disease in Childhood, 48, 127.

Wharton, B. A., Gough, G, and Pennock, C. A. (1973). The relationship of height and weight velocities of adolescent boys to the total hydroxyproline:creatinine ratio in their random urines. Clinical Science, 44, 359. 
Wharton, B. A., Brown, G., Rayner, P. H. W., Howells, G., and Pennock, C. A. (1974). Urinary hydroxyproline in children with growth hormone deficiency, clinical value in diagnosis and prognosis. Archives of Disease in Childhood, 49, 159.

Wharton, B. A., Gough, G., Williams, A., Kitts, S., and Pennock, C. A. (1972). Urinary total hydroxyproline:creatinine ratio. Range of normal , and clinical application in British children. Archives of Disease in Childhood, 47, 74.

Younoszai, M. K., Andersen, D. W., Filer, L. J., and Fomon, S. J. (1967). Urinary excretion of endogenous hydroxyproline by normal male infants. Pediatric Research, 1, 266.

Younoszai, M. K., Kacic, A., Dilling, L., and Haworth, J. C. (1969). Urinary hydroxyproline:creatinine ratio in normal term, preterm and growth retarded infants. Archives of Disease in Childhood, 44, 517.

Zorab, P. A., Clark, S., Harrison, A., and Seel, J. R. (1970). Hydroxyproline excretion and height velocity in adolescent boys. Archives of Disease in Childhood, 45, 763.

Susan Edwards, M. Hartog, C. A. Pennock, and J. APLEY

Bristol Royal Hospital for Sick Children, Bristol.

*Correspondence to Dr. C. A. Pennock, Research Floor, Outpatient's Bldg., Bristol Royal Infirmary, Bristol BS2 $8 \mathrm{HW}$.

\section{Clinical comparison between} glucose and sucrose additions to a basic electrolyte mixture in the outpatient management of acute gastroenteritis in children

Outpatient treatment of infantile gastroenteritis with an oral glucose electrolyte mixture has long been accepted (Darrow et al., 1949), although Ironside (1973) drew attention to the risk of osmotic diarrhoea with unrestricted use of glucose. Oral glucose reverses the hypersecretory state in cholera (Hirschhorn et al., 1968), in which oral sucrose is less effective (Nalin, 1975). Hirschhorn et al. (1973) recommended an oral glucose electrolyte solution for all children with acute gastroenteritis. Barnes and Townley (1973) showed that not only lactase but also, to a lesser extent, sucrase activity is depressed in the small intestinal mucosa of children with acute gastroenteritis. Clinical sucrose and lactose intolerance may result (Clayton, Arthur, and Francis, 1966).

Since 1953 a glucose electrolyte mixture (GEM) has been used effectively in the inpatient management of children with acute gastroenteritis in the Queen Elizabeth Hospital for Children. GEM however, once opened, has a short 'shelf life' because of the risk of bacterial contamination, so for outpatient management a basic electrolyte mixture to which sucrose is added for each feed has been used. In view of the reported benefits of oral glucose and the possible disadvantages of oral sucrose, we carried out a clinical trial of the relative merits of glucose or sucrose additions to a basic electrolyte mixture for treating children with acute gastroenteritis as outpatients.

\section{Methods}

From 2 January to 21 February 1975 all children attending the casualty department with acute gastroenteritis who did not require immediate admission were included in the trial. A total of 120 children were studied. Rectal swabs were taken in all cases. Treatment was by a standard regimen with initially a carbohydrate electrolyte solution, $150-170 \mathrm{ml} / \mathrm{kg}$ per 24 hours, followed by regrading by increments of one-fifth strength to the patients' normal milks. Toddlers were given a modified regimen with gradual reintroduction of a toddler diet.

In a randomized, double-blind fashion one half of the mothers were given sucrose and the other half glucose to add to the basic electrolyte solution. Feeds made up to $120 \mathrm{ml}$ had one flat $5 \mathrm{ml}$-measure of carbohydrate added, giving solutions of about $5 \%$ sucrose or glucose (see Table I). All the children were seen daily

\section{TABLE I}

Composition of electrolyte mixture with either glucose $5 \%$ or sucrose $5 \%$ added

\begin{tabular}{l|r}
\hline Electrolytes (mEq/l) & \\
Potassium & 28 \\
Sodium & 26 \\
Hydrogen & 4 \\
Chloride & 24 \\
Phosphate & 9 \\
Citrate & 3 \\
Osmolality (mOsm/1) & \\
with sucrose 5\% & 216 \\
with glucose 5\% & 351 \\
\hline
\end{tabular}

Note: The electrolyte solution was supplied in concentrated form containing potassium chloride $310 \mathrm{mg}$, potassium citrate $1.35 \mathrm{~g}$, sodium chloride $610 \mathrm{mg}$, and sodium dihydrogen phosphate $470 \mathrm{mg}$ in $100 \mathrm{ml}$ distilled water. Before use it was diluted five times with water, and sugar added as directed.

by one of us until they had clinically recovered. Recovery was assessed on the following criteria: no vomiting, no dehydration, clinically well, weight gain from onset, and stools returned to normal or to two to three soft stools a day-the pattern often seen for a time after acute gastroenteritis. The time taken to recover was noted in every child. Those who failed to recover were admitted to hospital (clinical failures.)

\section{Results}

Out of the 120 children 26 were excluded for various reasons (Table II). The ages of the remaining 94 children are listed in Table III. The outcome and the number of days taken to recover are shown in Table IV. Five (10\%) of the 